\title{
Non-IgE-mediated Cow Milk Allergy Manifesting as Severe Atopic Dermatitis
}

\author{
Nikcevska N, Petrovska S., \\ Zan Mitrev Clinic, R. Macedonia
}

\section{Background and Aims}

Cow's milk allergy (CMA) is the most common food allergy in infants and is associated with diverse clinical syndromes as a result of heterogeneous pathological immune responses to cow milk's proteins. CMA can manifest as an IgE-, non-lgE-mediated or mixed response. Atopic Dermatitis (AD) is considered to be an immune-mediated, inflammatory disease manifested by eczema, intense pruritus, dryness and erythema.

\section{Method}

We performed a radioallergosorbent test (RAST) and ImmunoCAP analysis of specific IgE antibodies against $\alpha$-lactalbumin, $\beta$-lactalbumin and casein. Possible Lactase gene polymorphisms were assessed via RTPCR.

A 5-months-old male infant presented with a severe form of $A D$, facial eczema and itching. Cow milk formula supplemented his breastmilk diet. The boy experienced delayed gastrointestinal involvement, bloating, and abdominal cramps and constipated to loose dark green stools.

The AD worsened with enlarging and merging of eczema, periorbital itching, erythema, palpebral oedema. We instructed the mother to switch to a dairy and allergen-free diet; extensively hydrolysed milk formula was used in addition to the breastmilk instead of the regular cow milk formula. The Finally, the AD was treated with hypoallergenic emollients.

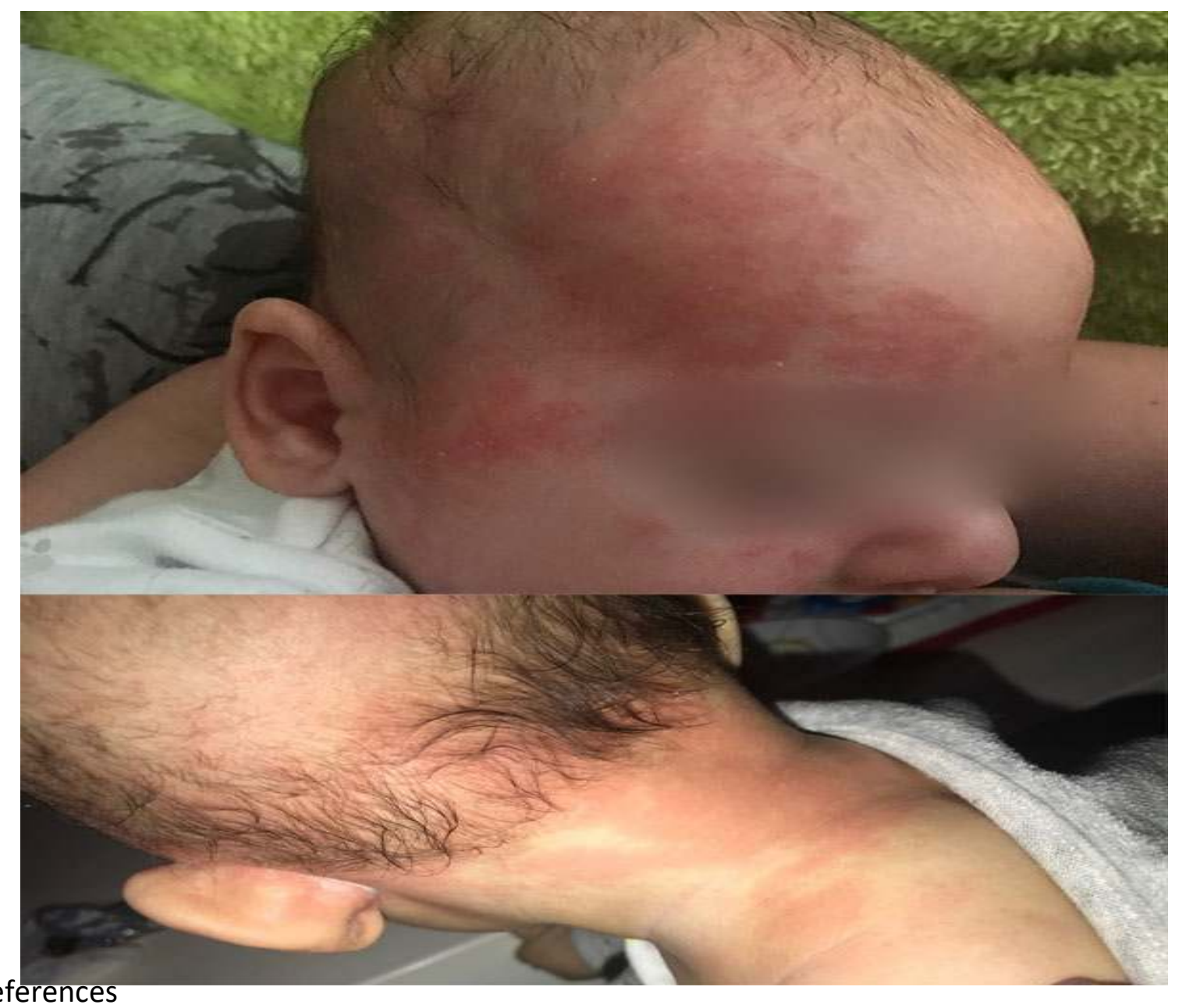

\section{Results}

RAST and immunoCAP were both negative. PCR for lactose intolerance revealed a C/T-13910 positive genotype. Following maternal and child diet adaptation and the use of emollients, the infant's clinical condition significantly improved with no signs of $A D$ and no abdominal symptoms.

\section{Conclusion}

Non-IgE-mediated cow milk allergy manifesting as severe Atopic Dermatitis and gastrointestinal manifestation is efficiently treated via maternal and child nutritional changes and emollients.

\begin{tabular}{|ll|}
\hline $\begin{array}{l}\text { Method PCR Lactose intolerance (C/T-13910) } \\
\text { Detected Allele 1: C } \\
\text { Allele 2 : C }\end{array}$ & POSITIVE \\
\hline Method RAST-CAP & \\
\hline Alfa-lactalbumin $<0.1 \mathrm{kU} / \mathrm{L}$ & NORMAL \\
\hline Beta-lactalbumin $<0.1 \mathrm{kU} / \mathrm{L}$ & NORMAL \\
\hline Kasein $<0.1 \mathrm{kU} / \mathrm{L}$ & NORMAL \\
\hline
\end{tabular}

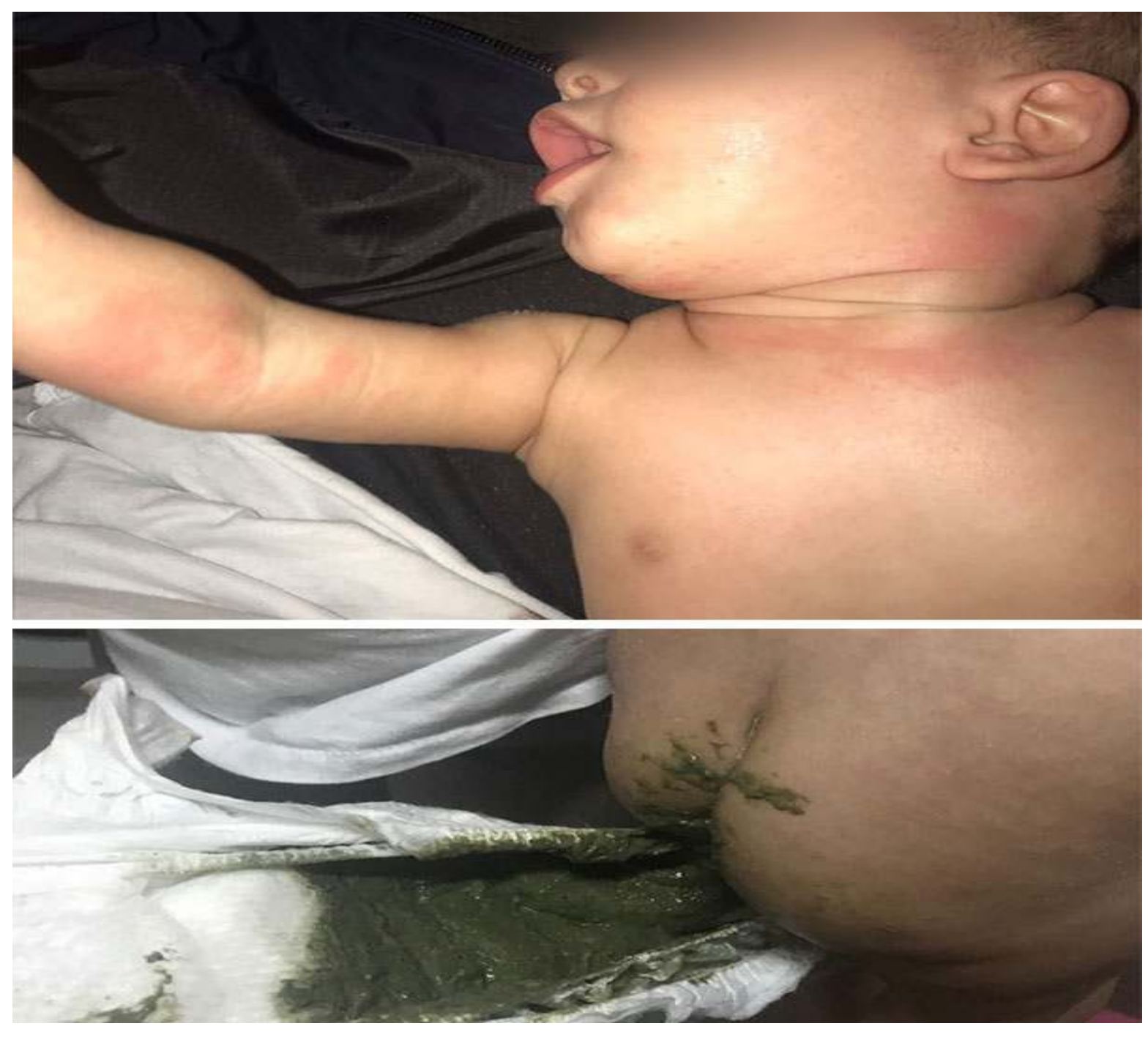

